\title{
Alteration kinetics of natural stones due to sodium sulfate crystallization: can reality match experimental simulations?
}

Teresa Diaz Gonçalves* and Vânia Brito

National Laboratory for Civil Engineering, Lisbon, Portugal

Av. Do Brasil 101, 1700-066 Lisbon

* teresag@Inec.pt; tel: + 351218443381

\section{Abstract}

Salt decay is a very destructive mechanism that frequently affects the porous building materials of our architectural heritage. Sodium sulfate is one of the salts found in this context. It usually demonstrates high destructive power in salt crystallization tests because it can crystallize not only during evaporative processes but also when the temperature drops or when the salt solution comes into contact with pre-existing crystals. However, the use of extreme temperatures or successive wet/dry cycles also makes these tests unrepresentative of reality.

To verify whether sodium sulfate can also be so destructive in field conditions, we have performed crystallization tests consisting of a single isothermal drying event. Three natural stones, relevant for the architectural heritage, were used for the purpose: Bentheimer sandstone, Ançã limestone, and a current Portuguese limestone of low porosity. The stones gave rise to distinct salt decay patterns: efflorescence, multilayer delamination and unilayer delamination, respectively. These morphological alterations were characterized at the micrometre scale by a new method based on what we have called the alteration kinetics curve. Such curve is calculated from topographic profiles obtained by a non-contact optical technique. The multilayer and unilayer delamination decay were also monitored by timelapse photography.

The work led us to conclude that sodium sulfate can indeed be also very destructive in fieldrepresentative conditions. Moreover, it showed that the optical method can be a valuable aid in the development of more realistic salt crystallization tests. 